\title{
Una propuesta didáctica para la enseñanza-aprendizaje de insectos, plantas y el problema de la pérdida de polinizadores
}

\author{
Blanca Puig (D), Borja Gómez Prado (D) \\ Departamento de Didácticas Aplicadas, Facultad de Ciencias de la Educación, Universidade de Santiago de \\ Compostela (USC).Santiago de Compostela.España.blanca.puig@usc.es,borja.gomez:prado@usc.es
}

[Recibido: 26 abril 2020. Revisado: 11 septiembre 2020. Aceptado: 20 mayo 2021]

Resumen: Se presenta un diseño didáctico llevado a cabo en formación inicial de profesorado de Educación Primaria alrededor de los insectos, las plantas y el problema de la pérdida de polinizadores. Pretendemos promover la alfabetización científica y el debate socio-científico sobre un tema de gran importancia en la actualidad. La propuesta se fundamenta en los diseños basados en la investigación y utiliza un enfoque constructivista basado en una metodología centrada en las prácticas científicas. Las actividades de la propuesta involucran a los/las participantes en la aplicación de conocimientos sobre plantas e insectos, la identificación de relaciones de polinización entre ellos, así como en el análisis crítico mediante pruebas. Mediante este diseño pretendemos contribuir a la investigación sobre ambientes de enseñanza y contextos de aprendizaje para la mejora de la formación científica básica mediante prácticas científicas en formación inicial de profesorado.

Palabras clave: Diseño didáctico, formación inicial de profesorado de primaria, insectos, plantas, pérdida de polinizadores.

A teaching sequence for teaching and learning about insects, plants and the problem of loss of pollinators

Abstract: This article presents the design of a teaching sequence carried out in Primary Pre-service teaching training about insects, plants and the problem of loss of pollinators. We aim to promote scientific literacy around these topics along with critical analysis of a relevant socio-scientific issue nowadays. The proposal is framed in design-based research and uses a constructivist approach based in a methodology in which scientific practices are central. The activities of the unit engage participants in the application of knowledge about insects and plants, the identification of pollination relationships, along with the critical analysis using evidence. We aim to contribute to research about learning environments and contexts to improve scientific education through scientific practices in initial teacher education.

Keywords: Teaching sequence; primary teachers training; insects, plants, loss of pollinators.

Para citar este artículo: Puig B. y Gómez B.(2021) Una propuesta didáctica para la enseñanza-aprendizaje de insectos, plantas y el problema de la pérdida de polinizadores. Revista Eureka sobre Enseñanza y Divulgación de las Ciencias 18(3), 3203. doi:10.25267/Rev_Eureka_ensen_divulg_cienc.2021.v18.i3.3203

\section{Introducción}

La pérdida de biodiversidad animal y vegetal en la Tierra es una problemática conocida desde hace tiempo. Tradicionalmente, en el abordaje de este problema los animales vertebrados han ocupado el centro de atención. Es en las dos últimas décadas cuando los invertebrados comienzan a recibir la atención merecida, motivada entre otros factores, por la creciente pérdida de insectos polinizadores (Sánchez-Bayo y Wyckhuys 2019). Esta pérdida es particularmente preocupante debido al importante papel que ejercen estos organismos en el mantenimiento del equilibrio de los ecosistemas y en la producción mundial de alimentos (Allsopp, Lange y Veldtman 2008). Se estima que, del total de plantas angiospermas, un 90\% se reproducen gracias a la polinización mediada por los insectos (Ollerton, Winfree y Tarrant 2011); y hasta un 35\% de la producción mundial de alimentos está basada directamente en los servicios ecosistémicos de insectos polinizadores (Klein et al., 2007). Los motivos de este 
declive son diversos y en general sinérgicos entre ellos (Watanabe, 2008). Por ejemplo, en el caso de las abejas, existen varios factores que podrían interactuar, como la existencia de parásitos introducidos, el uso de pesticidas neo-nicotinoides o la pérdida de hábitats en favor de los monocultivos, entre otros.

Ante esta situación y la necesidad de formar al futuro profesorado de primaria en el abordaje de estos temas, surge el diseño didáctico «Insectos, plantas y pérdida de polinizadores», que presentamos en este artículo. La propuesta pretende promover la alfabetización científica sobre plantas e insectos, en particular el aprendizaje de contenidos relacionados con la biología de plantas e insectos polinizadores y las relaciones que se establecen entre ellos. La finalidad del diseño es promover el aprendizaje de contenidos científicos relacionados con la polinización, así como el desarrollo de conocimientos didácticos sobre la enseñanza de estos contenidos y abordaje de problemas socio-científicos mediante prácticas científicas. Se pretende que los/las futuros/as docentes aprendan de manera implícita cómo llevar a la práctica actividades que implican el desempeño de prácticas científicas mediante la propia experiencia.

Los insectos, las plantas y la polinización forman parte de los contenidos relacionados con los seres vivos del currículo de ciencias naturales de Educación Primaria. Sin embargo, su enseñanza plantea dificultades asociadas a diversos factores cognitivos y emocionales. La falta de conocimientos científicos genera inseguridades por parte de los/las futuros docentes a la hora de introducir debates socio-científicos, que requieren del dominio de estrategias para guiar estos debates (Osborne, Simon, Christodoulou, Howell, Richardson y Richardson 2013).

La propuesta «Insectos, plantas y pérdida de polinizadores» se enmarca dentro los diseños basados en la investigación (DBI), cuyo objetivo es generar conocimiento sobre las condiciones de enseñanza mediante el diseño y desarrollo de investigación educativa en los entornos de aula (Guisasola Aranzabal, Ametller y Zuza 2020). El diseño es coherente con los DBI (Couso 2016; Sandoval y Bell 2004) que incluyen varias fases de investigación para poder mejorar las tareas, así como la enseñanza-aprendizaje de estos contenidos. El valor didáctico de la propuesta radica en la aplicación del marco de las prácticas científicas en la enseñanza de la polinización, temática que apenas ha sido investigada desde la didáctica de las ciencias. De acuerdo con Martí (2012), entendemos que en la formación de profesorado de primaria la actividad debe girar en torno a la construcción de explicaciones sobre el mundo natural y sobre cómo funciona la ciencia, siendo la pérdida de polinizadores un fenómeno relevante que posibilita el aprendizaje de cuestiones socio-científicas mediante prácticas científicas.

\section{Prácticas científicas y problemas socio-científicos en la educación científica básica}

Las actuales reformas educativas instan a una educación científica básica que permita al alumnado experimentar un aprendizaje científico riguroso y significativo (Roth 2014). De acuerdo con González-García (2015), las dificultades para la enseñanza de las ciencias en los niveles básicos, entre otras variables, son atribuibles a una carencia de conocimientos en los contenidos a enseñar y en cómo enseñarlos. Por otro lado, la investigación en didáctica de las ciencias pone de relieve los beneficios de una enseñanza de las ciencias centrada en los procesos de la ciencia y prácticas científicas desde las edades tempranas (Martí 2012); así como la necesidad de introducir cuestiones socio-científicas para lograr un aprendizaje significativo. Desde el punto de vista curricular y los Next Generation Science Stantards (NGSS Lead States 2013), las prácticas científicas son, junto a las ideas clave y los conceptos transversales, una de las tres dimensiones del aprendizaje de ciencias. Por prácticas científicas entendemos las "formas específicas en las que los miembros de una comunidad proponen, justifican evalúan y 
legitiman enunciados de conocimiento en un marco disciplinar (...)" (Kelly 2008 pp.99). Situar la participación en las prácticas científicas en el centro de la enseñanza de las ciencias implica entender que aprender ciencias conlleva participar en los objetivos epistémicos de la ciencia (Kelly 2008). La enseñanza de ciencias en primaria constituye una oportunidad para involucrar al alumnado en la comprensión y explicación de fenómenos naturales mediante el desempeño de prácticas científicas como la argumentación, modelización e indagación (Martí 2012). El alumnado de esta etapa es capaz de participar en estos procesos (Metz 2000), sin embargo, continúa siendo un desafío para el profesorado apoyar al alumnado en este sentido.

Las actividades que se presentan están diseñadas para practicar la argumentación y modelización científica. La argumentación puede definirse como la evaluación de enunciados de conocimiento a partir de las pruebas disponibles (Jiménez Aleixandre 2020). Esta evaluación es una práctica necesaria para decidir qué teoría o explicación de un fenómeno natural es mejor (Jiménez Aleixandre y Puig 2013). La modelización se define como la actividad científica de construir modelos, una actividad esencial de la ciencia y escolar, que implica expresar, usar, evaluar y revisar modelos (Couso 2020).

Esta propuesta constituye un ejemplo de cómo articular este marco introduciendo un problema socio-científico, la pérdida de polinizadores, cuyo análisis crítico requiere aplicar el modelo de polinización y el uso de datos de distinto tipo. La pérdida de insectos polinizadores constituye un problema socio-científico complejo de relevancia actual ocasionado por múltiples factores relacionados con la actividad humana cuya solución no es única (Watanabe 2008). Resolver este problema requiere cambios en las prácticas agrícolas, modelos de consumo, y otros de carácter político. De acuerdo con Díaz-Moreno y Jiménez-Liso (2011), consideramos que este tipo de problemas situados, de múltiples soluciones, permiten acercar al alumnado a la realidad de la ciencia en mayor medida que los problemas idealizados más tradicionales. Además, su introducción en el aula permite evidenciar los distintos factores sociales, cognitivos y emocionales que intervienen en la toma de soluciones sobre estos problemas. En la enseñanza de problemas ambientales esto es especialmente relevante debido a su naturaleza sistémica y multifuncional (Eilam 2002), lo que a su vez plantea desafíos al profesorado relativos al dominio de los distintos ámbitos que intervienen en la solución de estos problemas. Tomando como referencia todos estos aportes, se elabora el diseño cuya fundamentación didáctica y secuencia de actividades se desarrollan y discuten en las siguientes secciones.

\section{“Insectos, plantas y pérdida de polinizadores". Justificación del diseño}

La secuencia pretende formar al futuro profesorado de primaria en conocimientos relacionados con la biología de insectos y plantas comunes, la polinización y el problema de la pérdida de polinizadores, incorporando el marco de las prácticas científicas y el pensamiento crítico. Formar a los/las futuros/as docentes en dichos aspectos no resulta una labor sencilla, tal y como indica la investigación realizada en formación inicial del profesorado de Educación Primaria (Gómez Prado, Puig y Evagorou 2020). Entre las dificultades encontradas, caben ser destacadas la escasa formación científica, así como el rechazo que generan los insectos en la mayoría de los/las participantes (Wagler y Wagler 2011). Respecto a la enseñanza de vegetales, es necesario contemplar la denominada «ceguera de las plantas», término acuñado por Wandersee y Schussler (2001), para referirse a la tendencia general de infravalorar e ignorar la diversidad de especies vegetales incluyendo la falta de conocimientos botánicos básicos por la mayor parte del público. La propuesta que presentamos introduce algunos aspectos clave de botánica relacionados con las partes de una planta, sus principales funciones y la función de reproducción, cuya adecuada comprensión genera dificultades al alumnado de primaria (Jewell 2002; Schussler y Winslow 2007). La secuencia pretende facilitar el aprendizaje de las 
interacciones entre plantas e insectos mediante el abordaje de la polinización. El diseño parte de la visión de que, para lograr este objetivo, es necesario involucrar al profesorado en formación en el desempeño de prácticas científicas, así como en su análisis y reflexión (Jiménez-Liso, Martínez-Chico, Avraamidou y López-Gay 2019; Osborne 2017, entre otros). La secuencia "Insectos, plantas y pérdida de polinizadores" implica a los futuros/as docentes en las prácticas de argumentación y modelización, usando como contexto la evaluación de explicaciones en base a pruebas sobre el fenómeno relacionado con la pérdida de polinizadores y el análisis de diversos modelos representados para explicar este problema, entre otros aspectos.

El diseño fue elaborado por los propios autores, implicados en la formación inicial del profesorado de primaria. Uno de ellos es experto en entomología y trabaja en proyectos de divulgación de insectos en centros educativos. Las seis actividades de la secuencia (ver figura 1) están interrelacionadas y se distribuyen en seis sesiones consecutivas. Se ordenan de acuerdo con el criterio didáctico de complejidad y demanda cognitiva de los contenidos abordados. Es decir, los conocimientos a aplicar van aumentando en las distintas tareas, siendo necesario tener que aplicar y relacionar más nociones a medida que se avanza en la unidad. Además, consideramos necesario partir de una tarea inicial que estimule al alumnado y permita capturar sus ideas, intereses y emociones hacia los insectos, antes de llevar a cabo el resto de las tareas. Pretendemos de este modo identificar el tipo de emociones que suscitan los insectos, comprobar en qué medida generan o no rechazo entre los/las futuros docentes, y afectan a su interés por el aprendizaje de insectos.

El problema socio-científico se introduce en la última sesión, por requerir manejar diversos contenidos abordados en las actividades previas. La figura 1 muestra un resumen de las seis actividades de la propuesta, las tareas que implican y los objetivos de aprendizaje que se persiguen en cada una de ellas.

\begin{tabular}{|c|c|c|c|c|c|c|c|}
\hline \multicolumn{2}{|c|}{$\begin{array}{l}\text { Actividad } 1 \text { - INSECTOS Y EMOCIONES } \\
\text { (Actitudes y emociones) }\end{array}$} & & \multicolumn{2}{|c|}{$\begin{array}{c}\text { Actividad } 2 \text { - LAS ABEJAS Y SUS } \\
\text { COLMENAS } \\
\text { (Modelos materiales) }\end{array}$} & & \multicolumn{2}{|c|}{$\begin{array}{c}\text { Actividad } 3 \text { - OBSERVAR INSECTOS. } \\
\text { ¿QUÉ PARTES DEL INSECTO SE USAN } \\
\text { EN LA POLINIZACIÓN? } \\
\text { (Observación e identificación de ejemplares) }\end{array}$} \\
\hline $\begin{array}{l}\text { Preguntas abiertas } \\
\text { sobre conocimientos } \\
\text { previos e interés y } \\
\text { emociones causadas } \\
\text { por los insectos. }\end{array}$ & $\begin{array}{l}\text { Quiz online sobre } \\
\text { cuestiones básicas de } \\
\text { insectos. }\end{array}$ & & $\begin{array}{l}\text { Preguntas iniciales } \\
\text { sobre las abejas y sus } \\
\text { colmenas. }\end{array}$ & $\begin{array}{c}\text { Evaluación en grupo de } \\
\text { diversos modelos de } \\
\text { colmenas y de las formas } \\
\text { de representación de sus } \\
\text { diferentes componentes } \\
\text { en base a criterios. }\end{array}$ & & $\begin{array}{l}\text { Elaborar un dibujo de } \\
\text { un insecto e indicar } \\
\text { sus partes. }\end{array}$ & $\begin{array}{l}\text { Observar ejemplares } \\
\text { de insectos a la lupa } \\
\text { estereoscópica } \\
\text { e identificar sus } \\
\text { partes y estructuras } \\
\text { morfológicas. }\end{array}$ \\
\hline \multicolumn{2}{|c|}{$\begin{array}{l}\text { Objetivos de aprendizaje: } \\
\text { 1. Expresar las emociones que se sienten con los } \\
\text { insectos. } \\
\text { 2. Comunicar ideas y conocimientos previos sobre } \\
\text { insectos. } \\
\text { 3. Comparar ideas previas con datos científicos sobre } \\
\text { insectos. } \\
\text { 4. Utilizar herramientas de aprendizaje innovadoras. }\end{array}$} & \multirow[t]{2}{*}{$\rightarrow$} & \multicolumn{2}{|c|}{$\begin{array}{l}\text { Objetivos de aprendizaje: } \\
\text { 1. Usar criterios para evaluar los modelos en ciencia y } \\
\text { las diversas representaciones de fenómenos } \\
\text { biológicos. } \\
\text { 2. Desarrollar la capacidad de expresar y argumentar } \\
\text { las opiniones en un grupo. } \\
\text { 3. Desarrollar espiritu crítico respecto a las represen- } \\
\text { taciones científicas. }\end{array}$} & \multirow[t]{2}{*}{$\rightarrow$} & \multicolumn{2}{|c|}{$\begin{array}{l}\text { Objetivos de aprendizaje: } \\
\text { 1. Identificar las partes de un insecto, en particular las } \\
\text { estructuras que intervienen en la polinización. } \\
\text { 2. Desarrollar destrezas de observación e } \\
\text { identificación. } \\
\text { 3. Contrastar las expresiones en dibujos elaboradas } \\
\text { con las observaciones a lupa de los insectos reales. }\end{array}$} \\
\hline & & \\
\hline \multicolumn{2}{|c|}{$\begin{array}{l}\text { Actividad } 4 \text { - APRENDER SOBRE } \\
\text { PLANTAS CLASIFICÁNDOLAS } \\
\text { (Clasificación de plantas) }\end{array}$} & & \multicolumn{2}{|c|}{$\begin{array}{c}\text { Actividad } 5 \text { - CADA INSECTO } \\
\text { CON SU FLOR } \\
\text { (Establecer relaciones para elaborar } \\
\text { modelos materiales) }\end{array}$} & \multicolumn{3}{|c|}{$\begin{array}{l}\text { Actividad } 6 \text { - ¿ES LA PÉRDIDA DE LOS } \\
\text { POLINIZADORES UN PROBLEMA } \\
\text { SOCIO-CIENTÍFICO? } \\
\text { (Argumentar sobre una CSC en base a pruebas) }\end{array}$} \\
\hline $\begin{array}{l}\text { Clasific } \\
\text { de orig } \\
\text { base } \\
\text { previos } \\
\text { éstos co } \\
\text { cientíic }\end{array}$ & $\begin{array}{l}\text { productos } \\
\text { vegetal en } \\
\text { criterios } \\
\text { contrastar } \\
\text { os criterios } \\
\text { botánicos. }\end{array}$ & & $\begin{array}{l}\text { Establecer relaciones } \\
\text { especificas entre } \\
\text { plantas y } \\
\text { polinizadores. }\end{array}$ & $\begin{array}{l}\text { Elaborar un modelo } \\
\text { material de } \\
\text { polinización. }\end{array}$ & & $\begin{array}{l}\text { Uso de } p \\
\text { argument } \\
\text { problema d } \\
\text { insectos p } \\
\text { toma de deci } \\
\text { selección de }\end{array}$ & $\begin{array}{l}\text { as para } \\
\text { erca del } \\
\text { érdida de } \\
\text { adores, la } \\
\text { s éticas y la } \\
\text { formación. }\end{array}$ \\
\hline \multicolumn{2}{|c|}{$\begin{array}{l}\text { Objetivos de aprendizaje: } \\
\text { 1. Aplicación de conocimientos sobre plantas y } \\
\text { morfología floral. } \\
\text { 2. Usar criterios para clasificar algunas plantas con } \\
\text { flores. } \\
\text { 3. Establecer relaciones de causalidad entre las } \\
\text { propiedades de las plantas y su origen botánico. }\end{array}$} & & \multicolumn{2}{|c|}{$\begin{array}{l}\text { Objetivos de aprendizaje: } \\
\text { 1. Valorar e identificar la diversidad de relaciones } \\
\text { ecológicas existentes entre insectos polinizadores y } \\
\text { plantas. } \\
\text { 2. Usar pruebas para establecer relaciones entre } \\
\text { plantas y polinizadores. } \\
\text { 3. Interpretar los datos de una tabla. }\end{array}$} & & \multicolumn{2}{|c|}{$\begin{array}{l}\text { Objetivos de aprendizaje: } \\
\text { 1. Practicar la argumentación y el uso de pruebas en } \\
\text { el análisis de un problema socio-científico. } \\
\text { 2. Valorar la importancia de los insectos } \\
\text { polinizadores y su papel en los ecosistemas. } \\
\text { 3. Desarrollar espíritu crítico respecto a la } \\
\text { información y cuestionar el origen de la misma. }\end{array}$} \\
\hline
\end{tabular}

Figura 1. Resumen de las actividades de la propuesta didáctica y objetivos de aprendizaje que persiguen. 
Se trata de una secuencia enmarcada en el DBI (Garrido y Couso 2015). Esta metodología se define como el diseño, implementación, evaluación y rediseño de productos curriculares de mediana escala que cubren la enseñanza y el aprendizaje de un tema específico (Guisasola y Oliva 2020), en este caso la polinización. Las actividades incluidas son el resultado de las mejoras realizadas por ambos autores, tras analizar los resultados obtenidos en un estudio piloto llevado a cabo en formación inicial de profesorado de primaria en dos cursos consecutivos anteriores. Las modificaciones más relevantes introducidas tras estos estudios piloto consistieron en: 1) para la actividad 1, reducir el número de imágenes y especies de insectos hasta obtener una selección de ocho especies de insectos e imágenes que producían las reacciones más significativas; 2) para la actividad 3, de observación de insectos, se incluyeron las fichas de apoyo para guiar la identificación de apéndices y estructuras morfológicas involucradas en la polinización que en el estudio piloto resultaban confusas de identificar para el alumnado; 3) para la actividad 5, la tabla de registro para cubrir datos relativos a características distintivas de insectos y flores para el establecimiento de relaciones de polinización se simplificó respecto al estudio piloto, tanto en número de especies como en parámetros; 4) para la actividad 6, de argumentación, se mejoraron los enunciados propuestos y se proporcionaron una serie de datos con el fin de estructurar más la tarea y facilitar la construcción de argumentos.

\section{Participantes y contexto}

La secuencia «Insectos, plantas y pérdida de polinizadores» se realizó con alumnado del Grado de Maestro/a en Educación Primaria $(\mathrm{N}=131)$, cursando una materia de tercer curso de didáctica de ciencias naturales en primaria cuya docencia se distribuye en sesiones expositivas e interactivas de hora y media. Se trata de una materia obligatoria centrada en el análisis didáctico de contenidos de ciencias naturales en el currículo de Educación Primaria. La materia tiene como fin capacitar a los futuros/as docentes para enfrentarse a los problemas específicos de la enseñanza de estos contenidos. Las actividades fueron realizadas en grupos de cuatro personas, como se acostumbra a trabajar en la materia, aunque en algunas tareas tienen que responder de manera individual a algunas preguntas y luego hacer una puesta en común. La secuencia se desarrolló en seis sesiones interactivas consecutivas (una actividad por sesión) integradas en los contenidos relacionados con la enseñanza de seres vivos y ecosistemas y problemas derivados de la pérdida de biodiversidad.

\section{Descripción de las actividades y resultados a destacar}

\section{Actividad 1 «Conocimientos previos y emociones sobre insectos»}

Planteamos esta primera actividad con el fin de indagar y hacer conscientes a los futuros/as docentes de sus propios intereses y emociones hacia los insectos. Consideramos, al igual que otros autores, que las emociones son importantes en cualquier proceso de enseñanzaaprendizaje (Merino, Gallego y Ochoa de Alda 2019). La actividad se desarrolla en tres partes. La primera consiste en un cuestionario individual formado por las preguntas de la tabla 1. Pretendemos incentivar la participación y conocer las ideas e interés del profesorado en formación por los insectos en general. Tras responder individualmente a las preguntas, se hace una puesta en común. 
Tabla 1. Preguntas formuladas en la primera parte de la actividad 1 "Insectos y emociones".

\begin{tabular}{l}
\hline Pregunta formulada \\
\hline ¿Cómo definirías lo que es un insecto? \\
\hline ¿De todo lo que sabes de los insectos, que destacarías? \\
\hline ¿Los insectos son animales que causan tu interés? Sí/No, justifica tu respuesta. \\
\hline ¿Los insectos son importantes? Sí/No, justifica tu respuesta. \\
\hline
\end{tabular}

La segunda parte, orientada a conocer sus emociones, presenta una serie de imágenes de insectos comunes, como las de la figura 2. Se solicita a los/las participantes que expresen y expliquen las emociones que les producen cada uno de los ejemplares mostrados. Con el fin de que se detengan a pensar sobre la(s) sensación(es) que les produce(n), lo que sienten, les pedimos que lo expliquen por escrito.

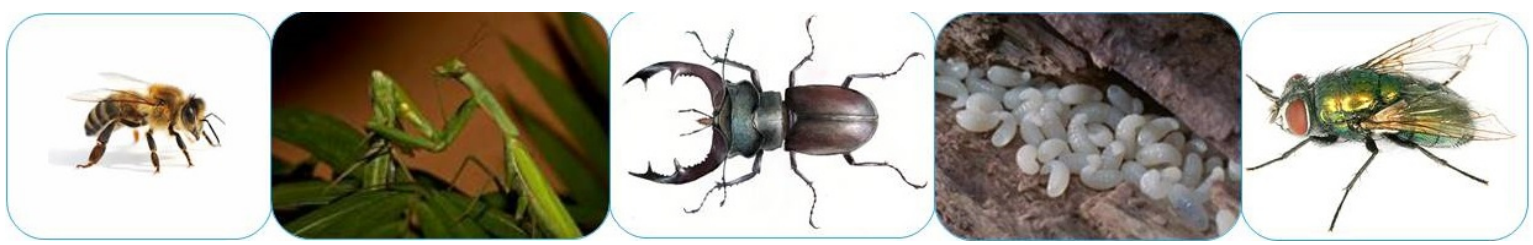

Figura 2. Ejemplos de imágenes proporcionadas en la segunda parte de la actividad 1 "Insectos y emociones".

Se proporcionan en total 16 imágenes de ocho especies de insectos: Escarabajo (Lucanus cervus); mariposa (Vanessa atalanta); mantis (Mantis religiosa); mariquita (Coccinella setempucntata); hormiga (Formica rufa); mosca (Lucilia Caesar); saltamontes (Schistocerca gregaria); abeja melífera (Apis mellifera). Las imágenes no fueron escogidas al azar, sino que se seleccionan insectos comunes, fáciles de ver; y que, según la investigación, provocan distintas emociones (Wagler y Wagler 2012). Por ejemplo, las mariquitas y mariposas son insectos de gran aceptación entre el público, mientras la mosca y el escarabajo no. También, teniendo en cuenta que el factor morfológico afecta a la percepción emocional (Wagler y Wagler 2012), seleccionamos algunas fotografías de formas larvarias.

La tercera parte de la actividad consiste en realizar un cuestionario kahoot con preguntas sobre contenidos básicos y curiosidades sobre insectos. Se pretenden abordar los objetivos específicos 3 y 4 (ver figura 1). Para que sea estimulante, el cuestionario se desarrolló a modo de concurso de conocimientos cuyos resultados se iban haciendo públicos a medida que se completaban las preguntas (Licorish, George, Owen y Daniel 2017). En total se formularon 20 preguntas sobre insectos que abarcan conceptos generales sobre evolución, diversidad y ecología (acceso en: https://create.kahoot.it/share/conoces-a-los-insectos/09fbbd05-d0494568-8dce-162a502f0365. Todas las respuestas permiten ser guardadas, lo que permite comprobar los conocimientos del alumnado y adecuar el nivel de contenidos a introducir en las restantes sesiones según el baremo obtenido.

\section{Resultados actividad 1}

Los resultados muestran similitudes con los de estudios previos sobre emociones hacia este grupo de organismos invertebrados (Kellert 1993). De las respuestas recogidas por el alumnado participante para cada una de las fotografías $(\mathrm{N}=2080)$, un $51.2 \%$ de las veces expresan, oralmente y por escrito, emociones negativas hacia los insectos mostrados en las imágenes; y un $33.2 \%$ emociones positivas. El porcentaje restante de forma neutral o indefinida. Referencias como «asco» y «miedo» aparecen de manera frecuente en sus respuestas escritas; en concreto, respecto a su morfología y comportamiento. Las emociones más positivas aparecen en respuesta a las imágenes de la mariquita y la mariposa adultas. 
La observación de los resultados del quiz kahoot, revelan que la mayoría de los/las participantes carecen de conocimientos básicos sobre insectos. Por ejemplo, cabe destacar que de entre las 20 preguntas realizadas, de un total de 117 test resueltos, sólo el 11\% identifica a los coleópteros como el grupo más diverso de insectos y sólo un $44 \%$ es capaz de enmarcar a los insectos dentro de la categoría taxonómica de clase. A la hora de identificar correctamente las estructuras morfológicas de los insectos, como la espiritrompa o las escamas de los lepidópteros, menos del 33\% de los/las participantes fueron capaces de hacerlo. También, más del 50\% presentaron dificultades relacionadas con la identificación de fenómenos que forman parte de los procesos vitales de algunos insectos, como la metamorfosis de los tábanos.

\section{Actividad 2. «Usar criterios para valorar modelos de colmenas»}

Esta actividad implica al alumnado en la evaluación de diversos modelos de colmenas en base a la observación de aspectos clave (ver tabla 2). Consideramos que las abejas y las colmenas constituyen un contexto idóneo para el aprendizaje de ciencias mediante el uso de modelos y la modelización. Se trata de insectos polinizadores fáciles de observar, cuyas interacciones dentro y fuera de colmena resultan claves en el proceso de polinización. La tarea utiliza 14 modelos de colmenas de abejas salvajes y domésticas, ubicados en un ecosistema concreto. Los modelos fueron elaborados por un grupo de futuros/as docentes de primaria en un estudio anterior (Puig y Evagorou 2020). Los materiales que utilizaron para su elaboración fueron elegidos libremente por los estudiantes, al igual que las formas de representación de cada elemento de la colmena.

La actividad se organizó a modo de exposición en la que se presentan los modelos científicos escolares en siete puestos (dos modelos por cada puesto), que representan algún aspecto concreto sobre las abejas y las colmenas: Puesto 1. La morfología de las abejas, Puesto 2. Las castas de la colmena; Puesto 3. Los panales de la colmena, Puesto 4. La forma de alimentación, Puesto 5. La producción de la miel, Puesto 6. La polinización. Las interacciones de las abejas fuera de la colmena. En cada puesto se exponen los dos modelos acompañados de un cartel (ver figura 3) con información científica sobre el fenómeno/objeto representado. El propósito de dar esta información era facilitar el análisis de los modelos en clave científica.

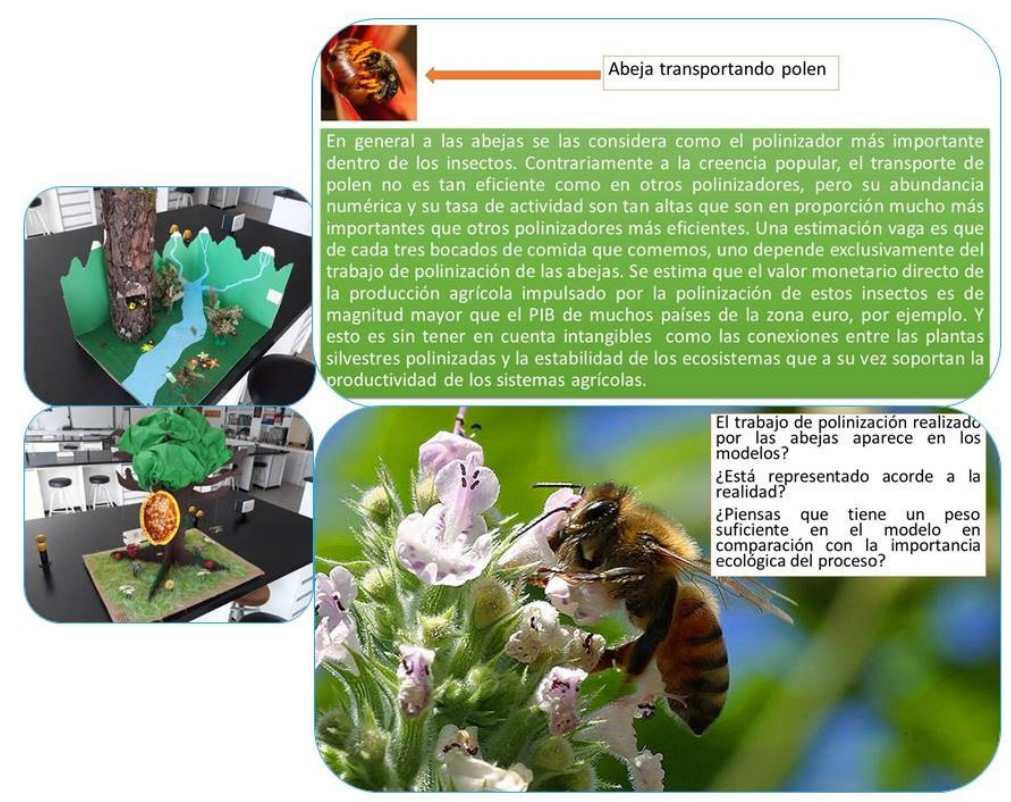

Figura 3. Ejemplos de dos modelos expuestos (las dos imágenes de la izquierda) y sus correspondientes carteles explicativos. 
La actividad requiere el uso de criterios para valorar la adecuación e idoneidad de los modelos expuestos y los elementos representados en los mismos. Para cada modelo se formularon las preguntas de la tabla 2. Se trata de cuestiones relativas a las formas de representación de distintos aspectos de los modelos que requieren usar criterios para decidir cuándo un modelo es adecuado o no de acuerdo con lo que se pretende representar y explicar. La actividad permite que los/las participantes expresen sus ideas ante preguntas científicas y utilicen datos e informaciones fiables para contrastar éstas y evaluar los modelos.

Tabla 2. Preguntas formuladas al alumnado en la tarea 2.

\begin{tabular}{|c|c|}
\hline $\begin{array}{l}\text { Puesto } 1 . \text { ¿Sabes cómo es el } \\
\text { cuerpo de una abeja? }\end{array}$ & $\begin{array}{l}\text { ¿Qué piensas sobre cómo las abejas están representadas en esta colmena? } \\
\text { ¿Crees que es una representación precisa de las proporciones y partes del } \\
\text { cuerpo de una abeja? ¿Por qué? }\end{array}$ \\
\hline $\begin{array}{l}\text { Puesto 2. ¿Qué castas de } \\
\text { abejas conoces? }\end{array}$ & $\begin{array}{l}\text { ¿Piensas que este modelo representa todos los tipos de abejas o castas que } \\
\text { existen en una colmena? ¿Por qué? } \\
\text { ¿Cuál crees que sería la reina? y ¿qué características del modelo te permiten } \\
\text { saberlo? }\end{array}$ \\
\hline $\begin{array}{l}\text { Puesto 3: ¿Cómo es una } \\
\text { colmena de abejas? } \\
\text { Descríbela brevemente. }\end{array}$ & $\begin{array}{l}\text { ¿Es la estructura de la colmena representada acorde a la realidad? ¿Por qué? } \\
\text { ¿En la realidad lo panales de abejas son de la misma manera que en la } \\
\text { representación de los modelos? ¿Por qué? }\end{array}$ \\
\hline $\begin{array}{l}\text { Puesto 4. ¿De qué se } \\
\text { alimentan las abejas? }\end{array}$ & $\begin{array}{l}\text { ¿Están los distintos tipos de alimentación representados en el modelo? ¿Por } \\
\text { qué? }\end{array}$ \\
\hline Puesto 5. ¿Qué & ¿Aparece la producción de miel representada en el modelo? \\
\hline $\begin{array}{l}\text { Puesto 6. ¿Qué es la } \\
\text { polinización? Explícalo con } \\
\text { tus palabras. }\end{array}$ & $\begin{array}{l}\text { ¿El trabajo de polinización realizado por las abejas aparece en los modelos? } \\
\text { ¿Está representado acorde a la realidad? ¿Piensas que tiene un peso suficiente } \\
\text { en el modelo en comparación con la importancia ecológica del proceso? }\end{array}$ \\
\hline $\begin{array}{l}\text { Puesto } 7 . \text { ¿Cómo } \\
\text { interaccionan con el } \\
\text { ecosistema? Pon algunos } \\
\text { ejemplos. }\end{array}$ & $\begin{array}{l}\text { ¿Qué ecosistema se representa? } \\
\text { ¿Qué elementos lo componen? } \\
\text { ¿Crees que este modelo representa bien la relación de las abejas con su } \\
\text { ecosistema circundante? ¿Por qué? } \\
\text { ¿Y las interacciones con otros animales? ¿Por qué? }\end{array}$ \\
\hline
\end{tabular}

La tarea se desarrolló en grupos pequeños, siendo el papel docente el de guía en el análisis de los modelos. Los docentes facilitaron la identificación de elementos que se representaban en los modelos, cuando el alumnado requería esta ayuda; y guiaban a los estudiantes en la búsqueda de información relevante para poder evaluar los modelos.

\section{Resultados actividad 2}

El análisis de criterios en esta tarea muestra que el 61\% de los/las participantes no fueron capaces de movilizar principios científicos para valorar los elementos representados en los modelos; utilizan más bien criterios artísticos u estéticos. Por ejemplo, para determinar si la representación del cuerpo de una abeja era precisa, los/las participantes hicieron referencia a detalles como el patrón de coloración o a aspectos estéticos. En concreto, criterios morfológicos como el número de apéndices y su posición corporal o la relación proporcional entre las diferentes partes del cuerpo apenas fueron movilizados para evaluar la idoneidad de los modelos. Cabe señalar que el patrón de coloración utilizado en las representaciones de abejas a evaluar, amarillo y negro es propio de himenópteros como las avispas y no de las abejas ibéricas, cuyas tonalidades tienden a ser negras sin bandeados amarillos muy visibles. Sin embargo, no lo cuestionaron. Otro ejemplo de uso de criterios estéticos en lugar de principios científicos, pudimos encontrarlo cuando el alumnado tenía que evaluar si el modelo representaba de manera adecuada la relación de las abejas con su ecosistema circundante. Los/as participantes valoraron positivamente que en la representación del ecosistema apareciesen representados animales vistosos como algunos mamíferos o peces en los ríos, más que la existencia de una diversidad de flora, necesaria para la subsistencia de las abejas. 


\section{Actividad 3. «Observar insectos ¿Qué partes del insecto se utilizan en la polinización?»}

La actividad consiste en observar e identificar algunos rasgos anatómicos de insectos que afectan a su modo de vida e intervienen directamente en la polinización. Para ello, creemos conveniente implicar al alumnado en la elaboración de dibujos y posterior observación de ejemplares. Los dibujos se consideran en este trabajo representaciones pictóricas construidas intencionalmente para lograr algún objetivo de aprendizaje y destinados a representar objetos con precisión (Van Meter y Garner 2005). A través de la elaboración de dibujos de insectos pretendemos que el alumnado exprese sus modelos mentales y contrasten éstos con la realidad observada en lupa. Para ello, fue necesario trabajar con ejemplares reales preservados en seco con alfileres. La tarea se llevó a cabo en tres partes que se describen a continuación. Se desarrolló en una sesión de una hora y media, dedicando 60 minutos a las dos primeras partes y 30 minutos la tercera parte de la actividad.

Parte 1: elaboración de dibujos de insectos. Los insectos para dibujar son seleccionados por Gómez Prado, Puig y Evagorou (2018) bajo los mismos criterios que en la actividad 1. Se corresponden con estos 12 ejemplares: abeja, abejorro, mariposa, saltamontes, mosca, mariquita, avispa, ciervo volador, escarabajo, mantis religiosa, polilla y libélula. Cada estudiante ha de elaborar un dibujo de dos ejemplares en el que traten de identificar las partes del cuerpo. Los docentes intervienen para indicar que los dibujos han de elaborarse en base a sus conocimientos previos (pudiendo basarse en imágenes que recuerden) procurando indicar en sus dibujos las partes del cuerpo.

Parte 2: observación de insectos e identificación de rasgos morfológicos clave mediante lupa estereoscópica. Proporcionamos tres fichas (ver figura 4) para que observen y clasifiquen los diferentes tipos de apéndices de los insectos proporcionados. Hacemos hincapié en todas aquellas adaptaciones morfológicas relevantes en la polinización de las plantas en aquellas especies que son polinizadoras. Por ejemplo, las escopas de las abejas y abejorros o el tórax velludo de los lepidópteros.

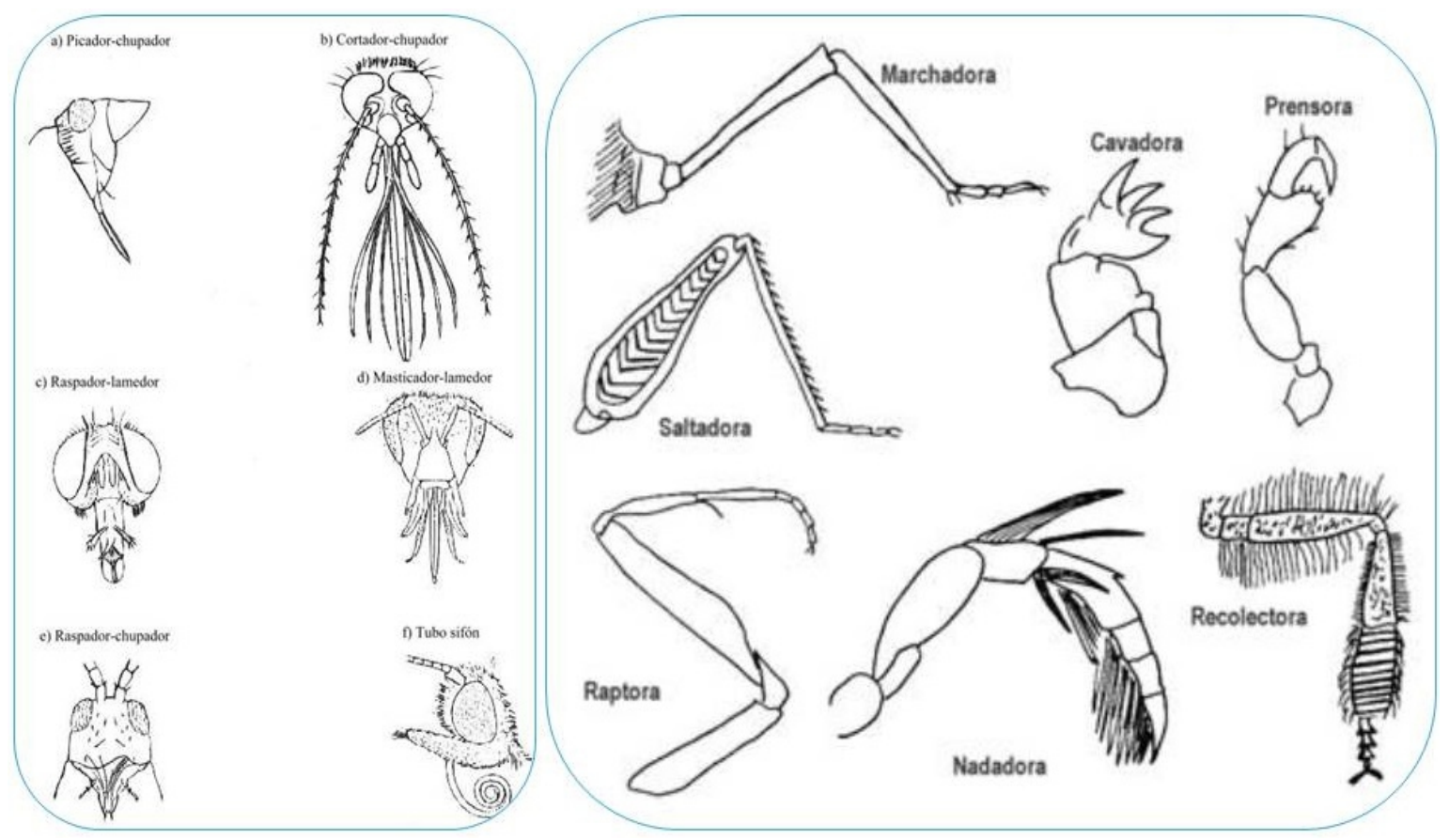

Figura 4. Ejemplos de fichas de apéndices proporcionadas en la actividad 3. A la izquierda aparatos bucales y a la derecha patas. 
Parte 3: Contrastar los dibujos con las observaciones a lupa. Se pide al alumnado que comparen la realidad aumentada con los dibujos elaborados y que comprueben en qué medida se ajustan. Los docentes guían esta parte de la actividad solicitando en primer lugar, que comparen sus dibujos con las observaciones a lupa de una forma global; y, en segundo lugar, que se detengan en las distintas partes del cuerpo usando las fichas.

\section{Resultados actividad 3}

El análisis de esta tarea permite identificar algunas dificultades por parte del alumnado a la hora de diferenciar partes del cuerpo. En la parte 1, los/las participantes hicieron dibujos de todos los insectos, sin ningún tipo de instrucción, sólo basándose en sus conocimientos previos. En general, más de tres cuartas partes de los dibujos elaborados son poco detallados y no diferencian segmentos corporales como el tórax y el abdomen. Tras la observación a lupa, los/las participantes volvieron a realizar sus dibujos y estos mejoraron en todos los casos como se puede comprobar en la figura 9. Los/as estudiantes destacaron como sorprendentes hechos que pudieron observar con las lupas, como la presencia de tres ocelos en la cabeza de las avispas o comprobar que lo que los lepidópteros tienen en sus alas no es un polvo como ellos creían, sino escamas.

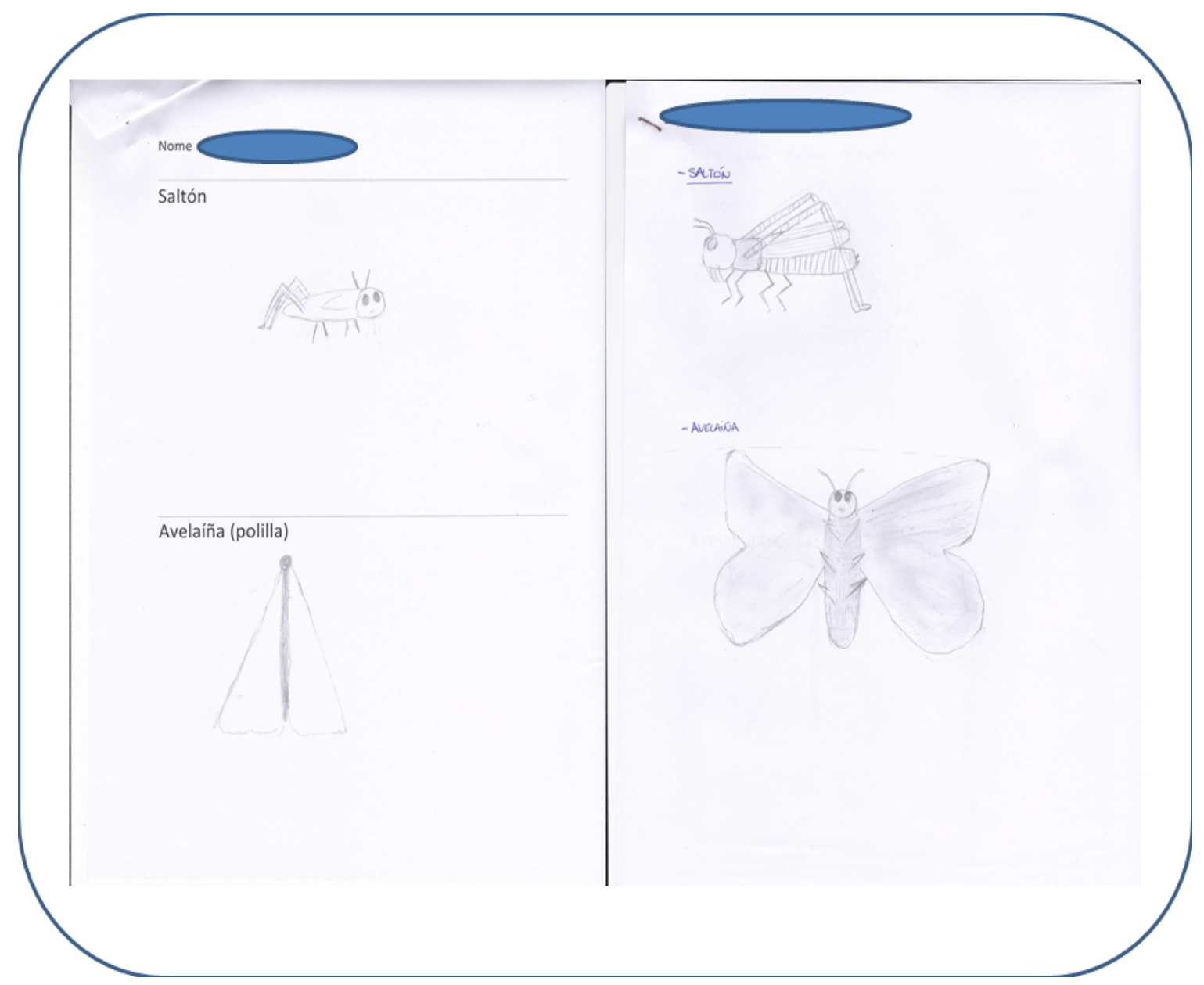

Figura 5. Dibujos de los/las participantes en la actividad 3. A la izquierda los dibujos elaborados en la primera parte de la actividad. A la derecha los dibujos tras la observación directa con lupa y el contraste morfológico de los apéndices. Se aprecia mucho más detalle y realismo, así como mejor correspondencia con las estructuras morfológicas como alas o antenas o patas tanto en forma como en posición. 


\section{Actividad 4. «Aprender sobre plantas clasificándolas»}

Esta actividad introduce a los/las participantes en el estudio de algunas plantas comunes y en su clasificación en base a sus estructurares florales, parte vinculada con la polinización. Para ello, presentamos una serie de productos de origen vegetal de consumo cotidiano: perejil, pipas de girasol, guisantes, tomate, tabaco, azúcar, cacahuetes, almendras, maíz, zanahoria, manzanilla, lechuga. La tarea comienza solicitando a cada grupo que clasifique estos productos bajo su propio criterio. Este criterio puede ser el color, su uso, o lo que decidan abiertamente. A continuación, hecha la clasificación, deben valorar la clasificación elaborada por otro grupo de forma crítica. Se trata de que pongan en común los criterios manejados y su pertinencia. Tras esta primera fase, se pide clasificar de nuevo los productos, pero esta vez, con arreglo a un criterio botánico. Es decir, han de basarse en la morfología de las flores, puesto que es en ellas y en sus estructuras donde puede verse el parentesco evolutivo. Se les facilitan una serie de fichas con dos fotografías por cada producto vegetal. Una imagen de la planta de la que procede, y otra con un detalle de la flor. La figura 6 muestra dos ejemplos.

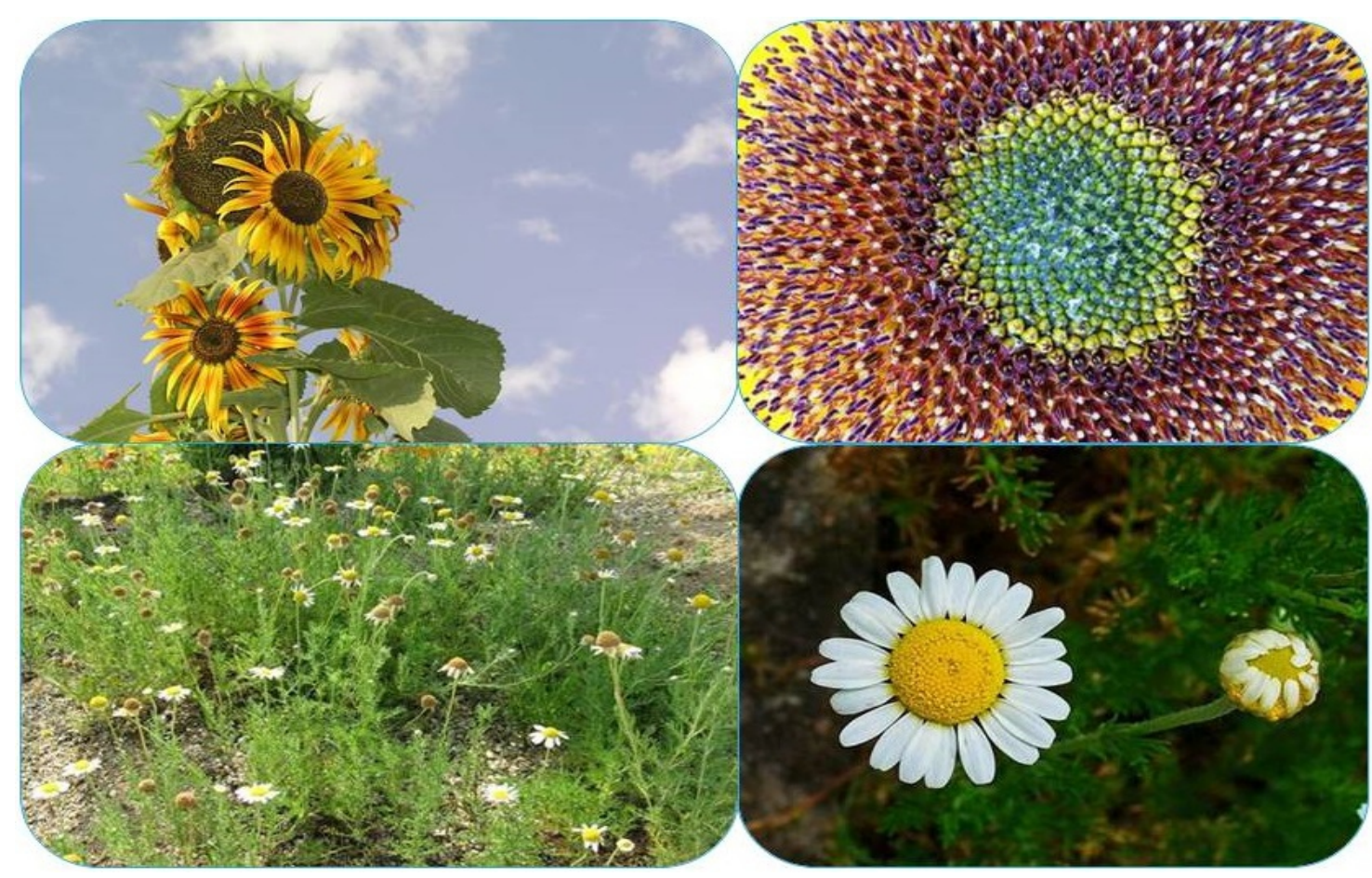

Figura 6. Ejemplos de fichas proporcionadas en la actividad 4. Se muestran dos plantas de la misma familia, comúnmente conocidas como compuestas, el girasol y la manzanilla. A la izquierda la imagen general y a la derecha la imagen detallada de la flor.

Hechas de nuevo las clasificaciones en base a criterios botánicos, se realiza una puesta en común. Si bien es cierto que del total de grupos analizados $(\mathrm{N}=33)$ la gran mayoría decide cambiar su criterio de clasificación en base a los nuevos datos $(\mathrm{N}=27)$, pero en ningún caso se logran identificar las similitudes morfológicas entre flores para agrupar los productos por familias como gramíneas, umbelíferas, etc. La gran mayoría de los nuevos criterios se basan en los colores de las flores, formas de la planta o los frutos que se obtienen, pero no buscan caracteres clave para la clasificación. La actividad termina con una explicación sobre las similitudes entre estos tipos de flores y las características de sus familias biológicas por parte de los docentes. Por ejemplo, el guisante y el cacahuete a priori son muy diferentes, sin embargo, ambos son legumbres ya que tienen una flor y características biológicas similares. Pretendemos incidir sobre algunas ideas clave en la clasificación de los seres vivos, las 
diferentes morfologías e introducir estructuras florales que intervienen en los diversos fenómenos de polinización.

\section{Resultados actividad 4}

Existen dificultades por parte de los/las participantes para encontrar un criterio científico o botánico a la hora de clasificar una planta, o encontrar similitudes entre las flores como ya se comentó en el anterior apartado donde se describió la actividad. No obstante, fueron capaces de aplicar criterios de clasificación alternativos adecuados como el uso o el procesado que llevaba el producto final. En particular, el criterio más utilizado fue la diferenciación entre los conceptos fruto seco, verdura y hortaliza con un 53\%, siguiendo en frecuencia la clasificación como productos saludables y no saludables con un $34 \%$.

\section{Actividad 5. «Cada insecto con su flor»}

Esta actividad aúna los dos grupos de organismos que se han trabajado previamente, insectos y plantas, y se basa en un diseño previo elaborado por los autores (2018). La tarea tiene como fin el uso de pruebas para establecer relaciones entre flores y polinizadores. Para ello, se facilitan unas fichas con datos sobre la biología y características de tres plantas y tres insectos que tienen una estrecha relación ecológica. Es el caso de los dípteros y la planta del aro común, por ejemplo. La figura 7 muestra una de las fichas proporcionadas.

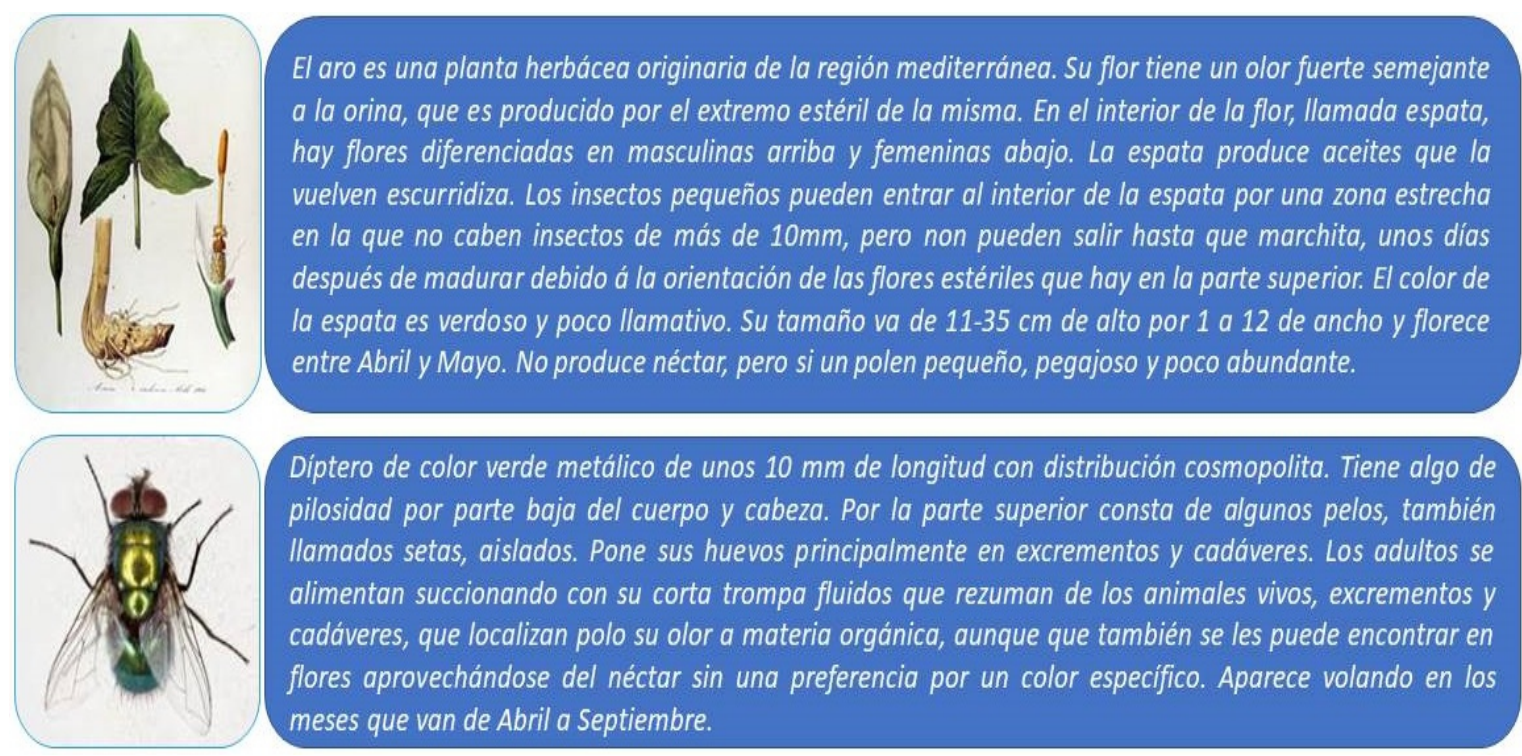

Figura 7. Fichas presentadas de los pares de insecto polinizador y planta polinizada e información contenida en ellas (elaboración propia), en este caso el aro, Arum italicum, y la mosca, Lucia caesar.

Tras presentar las fichas, solicitamos que cubran los datos de la tabla 3. A continuación, han de decidir qué datos consideran clave en las relaciones de polinización y que expresen sus ideas y razones que consideran a la hora de decidir por qué unos insectos polinizan a unas plantas y a otras no. En algunos casos esto puede ser debido a que la planta no florece durante el período en el que el insecto está activo. En otros porque la planta no permite el acceso del insecto al polen; o bien, porque la planta presenta estructuras específicas para atraer un tipo determinado de insecto. 
Tabla 3. Tabla para el registro de datos en la actividad 5.

\begin{tabular}{|c|c|c|c|c|c|c|}
\hline \multicolumn{3}{|c|}{ Organismos } & \multicolumn{3}{|c|}{ Características destacables } & \multirow[b]{2}{*}{$\begin{array}{c}\text { Preferencia de } \\
\text { olor } \\
\text { (Fuerte / } \\
\text { Suave / No) } \\
\end{array}$} \\
\hline Insectos & Tamaño & $\begin{array}{l}\text { Boca } \\
\text { (Larga, } \\
\text { corta) }\end{array}$ & $\begin{array}{c}\text { Alimento } \\
\text { (Néctar / polen / } \\
\text { ninguno de los dos) }\end{array}$ & $\begin{array}{c}\text { Preferencia } \\
\text { de color }\end{array}$ & $\begin{array}{c}\text { Temporada } \\
\text { de } \\
\text { aparición }\end{array}$ & \\
\hline \multicolumn{7}{|l|}{$\begin{array}{c}\text { Apis } \\
\text { mellifera }\end{array}$} \\
\hline \multicolumn{7}{|l|}{$\begin{array}{l}\text { Lucilia } \\
\text { sericata }\end{array}$} \\
\hline \multicolumn{7}{|l|}{$\begin{array}{l}\text { Vanessa } \\
\text { cardui }\end{array}$} \\
\hline Flores & Color & $\begin{array}{c}\text { Olor } \\
\text { (Si fuerte/ si } \\
\text { suave / no) }\end{array}$ & $\begin{array}{c}\text { Tamaño de la } \\
\text { abertura de acceso } \\
\text { (si tiene) }\end{array}$ & $\begin{array}{l}\text { Temporada } \\
\text { de floración }\end{array}$ & $\begin{array}{c}\text { Polen } \\
\text { (Mucho/ } \\
\text { Poco) } \\
\end{array}$ & $\begin{array}{c}\text { Néctar } \\
\text { (Mucho/ Poco / } \\
\text { No produce) }\end{array}$ \\
\hline \multicolumn{7}{|l|}{$\begin{array}{c}\text { Arum } \\
\text { italicum }\end{array}$} \\
\hline \multicolumn{7}{|l|}{$\begin{array}{c}\text { Prunus } \\
\text { dulcis }\end{array}$} \\
\hline $\begin{array}{c}\text { Buddleja } \\
\text { davidi }\end{array}$ & & & & & & \\
\hline
\end{tabular}

Finalmente, con los datos de la tabla cubierta, han de representar mediante un dibujo o esquema, que ellos mismos deciden de forma libre, el proceso de polinización con estos organismos. Un ejemplo es el de la figura 8.

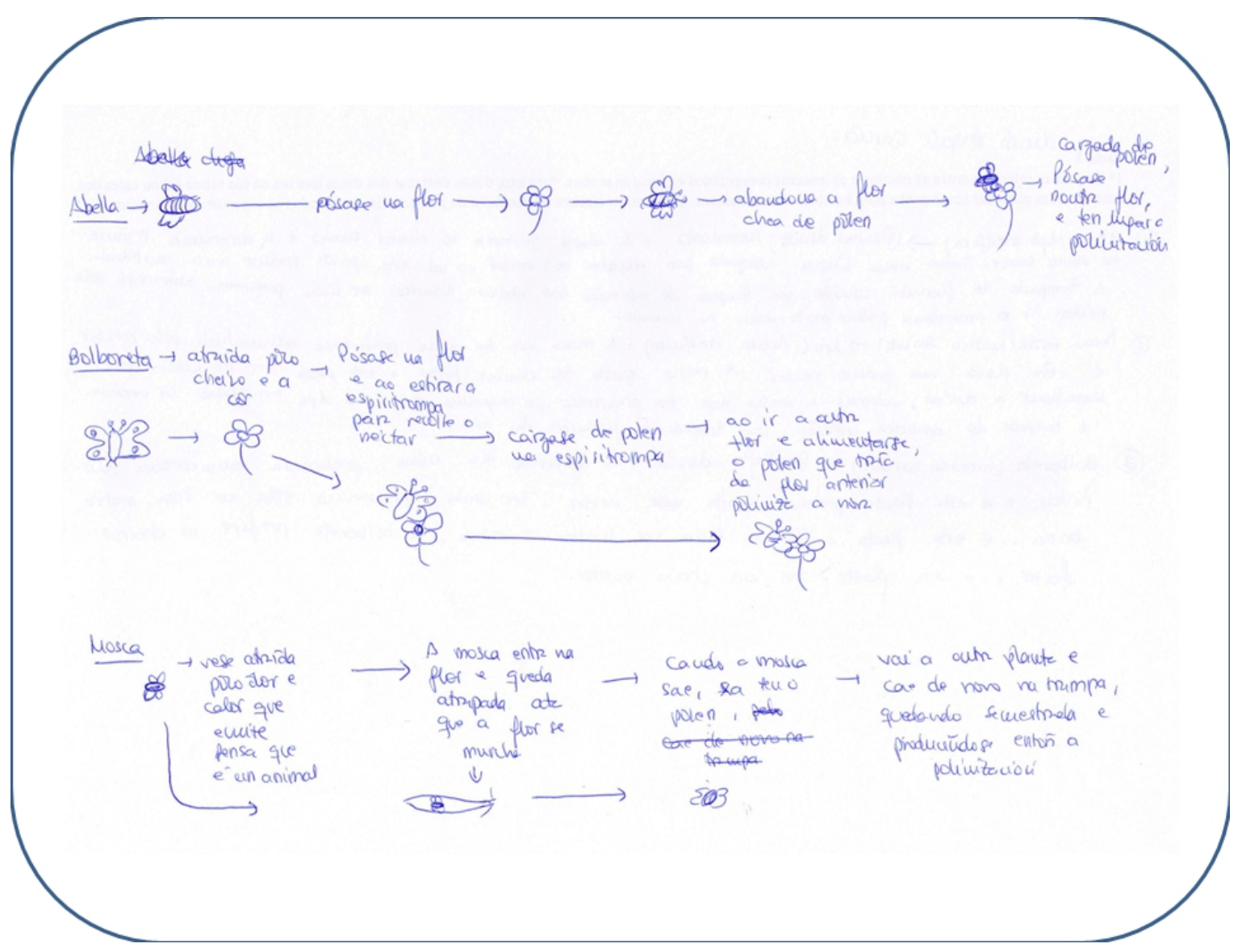

Figura 8. Ejemplo de los esquemas de polinización elaborados en la actividad 5. 
Se trata de representar la polinización en base a la información seleccionada y a las pruebas que consideran más importantes. El papel docente en esta actividad consistió en guiar al alumnado en el registro de datos en la tabla y en la identificación de características que ayudan a establecer relaciones de polinización entre los ejemplares de flores e insectos.

\section{Resultados de la actividad 5}

Todas/os las/los estudiantes fueron capaces de establecer conexiones adecuadas de polinización en base a la información proporcionada con la guía de los docentes. Un de las dificultades encontradas, que requirió de apoyo docente, fue identificar los factores limitantes que hacen que una especie sea capaz de polinizar o no una planta, como puede ser su tamaño, o la diferencia en la fenología. Más de la mitad del alumnado no fue capaz de identificar estos factores, a pesar de tenerlo escrito en sus tablas. La tarea permitió evidenciar la complejidad de la polinización y las relaciones entre organismos, aspectos que manifestaron los/las participantes.

\section{Actividad 6. «La pérdida de polinizadores a debate»}

La investigación sobre cuestiones socio-científicas pone de relieve las dificultades del alumnado en este contexto y la importancia del uso de noticias científicas a la hora de promover la argumentación (Jiménez-Liso, Hernández-Villalobos y Lapetina 2010). Planteamos en la última sesión de la secuencia un dilema que requiere poner en práctica los conceptos científicos previamente abordados para argumentar sobre un tema objeto de debate científico y social, la pérdida de polinizadores. La tarea se desarrolla en tres fases:

Fase 1. Presentación de una supuesta campaña ecologista en la que se plantean acciones para frenar la pérdida de insectos: «Desde Greenpeace, pedimos que firmes para exigir al Gobierno español que desarrolle un plan de acción integral para proteger a los insectos polinizadores. De las acciones de hoy dependen las generaciones futuras de humanos y otras especies. Firma para pedir a las autoridades españolas que protejan a los insectos polinizadores.»

Tras introducir la campaña, abrimos un debate. Los docentes animan al alumnado a participar y a expresar sus ideas, formulando algunas preguntas como: ¿Conocíais ya esta campaña de Greenpeace o es la primera vez que la veis?; ¿habéis participado en alguna campaña de recogida de firmas similar a esta?; ¿qué opináis sobre este tipo de campañas?; ¿creéis que son necesarias acciones de este tipo para proteger a los insectos polinizadores u a otras especies? Tras este primer intercambio de ideas, el alumnado muestra sus posiciones frente a la campaña, que da lugar a un debate entre partidarios y no partidarios de firmar la petición. Los docentes actúan de moderadores pidiendo al alumnado que argumente sus posiciones.

Fase 2. Presentación de una noticia sobre uno de los polinizadores en peligro, las abejas, y en relación con este problema, dos conclusiones con posiciones contrapuestas. Un enunciado hace referencia a que, si las abejas desparecen, al ser humano le quedarían cuatro años de vida. El otro indica que esto no ocurriría y que el problema no sería tan grave. El diseño se basa en una tarea previa (Puig, 2015). La noticia es:

«El trastorno del colapso de colonias (CCD) es un fenómeno en el que las abejas obreras de una colmena desaparecen bruscamente. Mientras que tales desapariciones han ocurrido en la historia de la apicultura, y se conoce por varios nombres, el síndrome ha sido renombrado como desorden del colapso de colonias a finales de 2006, en relación con un aumento drástico en el número de desapariciones de abejas en América del Norte. Apicultores europeos observaron fenómenos similares en Bélgica, Francia, los Países Bajos, Grecia, Italia, Portugal y España. Informes iniciales también han llegado de Suiza y Alemania, aunque en menor grado, 
mientras que en Irlanda del Norte sufrió una disminución superior al 50\%. Recuperado de: http://coronaapicultura.blogspot.com/2016/12/trastorno-del-colapso-de-las-colmenas.html»

Se abre un debate para el alumnado expongan su ideas y argumentos respecto a las dos conclusiones y expliquen con cuál estarían de acuerdo y por qué. El papel docente vuelve a ser el de moderadores en el debate, gestionando los turnos de palabra y solicitando al alumnado que razone sus posturas.

Fase 3. Presentación de dos enunciados contrapuestos sobre el problema de la pérdida de polinizadores y las posibles causas: la conclusión 1, que hace referencia a la interacción de distintos factores relacionados con la acción humana, como posible causa de la muerte de las abejas y otros polinizadores; y la conclusión 2, que apunta a la falta de datos para explicar este fenómeno. Se proporcionan una serie de datos (12 en total) relacionados con ambos enunciados, y se les pide que indiquen si son pruebas o no relacionadas con los enunciados, y si apoyan o no con fuerza las conclusiones (ver figura 8).

Nombre:

Prueba 1: Además de las abejas, existen
numerosos estudios que destacan el declive
de muchas especies de insectos
polinizadores, y también de aquellos que no
lo son.

Prueba 2: El ácaro Varroa destructor, por si mismo no es quién de acabar con una colmena, pero si que debilita a sus habitantes.

Prueba 3: La cantidad de neonicotinoides presentes en una planta tratada non es suficiente para causar la muerte de las abejas. Únicamente mueren los insectos que comen la planta directamente.

Prueba 4: La mayoría de los estudios sobre $\mathrm{CCD}$, no son realizados en condiciones ambientales normales $\mathrm{y}$ a gran escala, por lo que los datos non suelen ser extrapolables.

Prueba 5: En Galicia, el año pasado, el número de colmenas aumentó un $38 \%$

Prueba 6: En el terreno donde se plantan eucaliptos crecen muy pocas plantas.

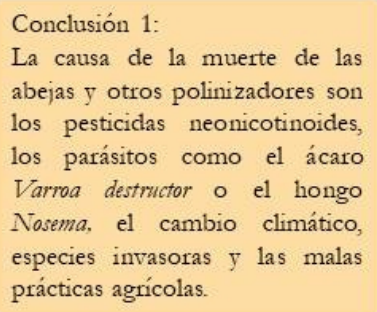

La causa de la muerte de las abejas $\mathrm{y}$ otros polinizadores son los pesticidas neonicotinoides, los parásitos como el ácaro Varroa destructor o el hongo Nosema, el cambio climático, especies invasoras $y$ las malas prácticas agrícolas.

\section{Conclusión 2}

Determinar si el desorden de colapso de las colonias ocurre realmente $y$ si está en realidad provocado por la acción humana es complicado pues a día de hoy aún non hay demasiados datos concluyentes.
Grupo:

Prueba 7: La Vespa velutina se extiende cada vez más por toda la Península Ibérica.

Prueba 8: El año 2016 fue considerado por los meteorólogos como el año más caliente desde que se tiene registro.

Prueba 9: Con los años existe una tendencia agraria a realizar grandes monocultivos extensivos, lo que hace que las abejas $y$ otros polinizadores dispongan de menos alimento para sus actividades.

Prueba 10: Algunos apicultores exageran las pérdidas sufridas cada año cuando aportan los datos de sus colmenas

Prueba 11: El presidente de Estados Unidos eliminó todo el presupuesto de investigación del departamento Federal de Agricultura correspondiente a las investigaciones en $\mathrm{CCD}$ por considerarlo carente de pruebas cientificas que lo justifiquen.

Prueba 12: El uso de los pesticidas neonicotinoides comenzó aproximadamente en los mismos años en los que se detectaron los primeros sintomas.

Figura 9. Conclusiones (centro) e informaciones proporcionadas para su evaluación (columnas laterales).

\section{Resultados actividad 6}

Los/las participantes se implicaron activamente en el debate y defendieron, en la mayoría de los casos, la petición al gobierno en defensa de los polinizadores. Los estudiantes que se opusieron a esta petición exponían que lo hacían por venir de una entidad con la que no se alineaban ideológicamente o porque no firmaban peticiones de ese tipo. A la hora de escoger entre ambos enunciados, la mayoría estaba de acuerdo con el más pesimista. Una minoría defendió que no sería tan grave si se puede paliar con tecnología en un futuro. Respecto a la capacidad para relacionar diferentes datos para apoyar o refutar las conclusiones, en muchos casos confundieron las conexiones. 


\section{Conclusiones e implicaciones para la práctica educativa}

El diseño presentado en este artículo tiene como principal aportación contribuir a la investigación sobre ambientes de enseñanza y contextos de aprendizaje para la mejora de la formación científica básica mediante prácticas científicas en formación inicial de profesorado. Hasta donde hemos podido saber, en la revisión de la literatura no existen secuencias de aprendizaje similares sobre insectos y el problema de la pérdida de polinizadores, por lo que esta propuesta podría servir como punto de partida o inspiración para futuros diseños de secuencias didácticas e investigaciones centradas en esta temática. Además, no hemos encontrado otros trabajos como este en nuestro contexto en formación inicial de profesorado, por lo que el presente artículo hace también una contribución en este sentido. Aunque en el contexto anglosajón existen algunas investigaciones sobre insectos y polinizadores (Wagler 2010; Wagler y Wagler 2011; 2012), en ningún caso, utilizan un enfoque de prácticas científicas.

El análisis de los resultados de las actividades de esta secuencia pone de relieve la necesidad de mejorar la formación científica básica de los futuros/as docentes sobre plantas e insectos, así como en prácticas como la clasificación de ejemplares en base a criterios científicos. También, se pone en evidencia la importancia de prestar atención a las emociones en la enseñanza de insectos, como apuntan estudios previos (Barrow 2002). La mayoría de los/las participantes expresaron emociones negativas hacia los insectos presentados, lo que, según autores como Wagler (2010), podría afectar a su interés por incluir estos organismos en la enseñanza de seres vivos en Educación Primaria. Aprender sobre insectos, plantas y las relaciones de polinización entre ellos, requiere entender características clave de estos organismos, sus funciones vitales y el papel de la polinización. Para ello, resulta necesaria su observación, identificación y clasificación, además de tareas que permitan relacionar ambos tipos de organismos. Sugerimos promover tareas que, como el caso de esta secuencia, permitan practicar estas destrezas en la formación docente, y a su vez, estimulen el interés por los insectos mediante el contacto directo con estos organismos, tal y como sugieren Wagler y Wagler (2011).

El uso de criterios por parte del alumnado para evaluar los modelos de colmenas (actividad 2) resultó útil para conocer e identificar sus ideas respecto a las características de las abejas, la estructura de una colmena, así como las interacciones entre ellas fuera y dentro de la colmena. Sin embargo, en futuras implementaciones es necesario previamente, hacer explícitos los objetivos de la modelización (Puig y Evagorou 2020), de tal forma que el alumnado sea consciente de que en la evaluación de modelos es necesario tener en cuenta no sólo la forma en que se representan los elementos/entidades a estudiar, sino también su potencial explicativo. La modelización, tal y como la define Couso (2020, p. 66) es «el proceso de elaborar representaciones simplificadas y parciales de objetos y/o fenómenos con el fin de describir, predecir o bien explicar aspectos que nos interesan sobre estos». Por lo tanto, la evaluación de modelos ha de conllevar el uso de criterios acordes a esta definición y al fin de la modelización.

En cuanto a otras formas de representación, consideramos que la elaboración de dibujos de insectos u otros organismos tiene el potencial de hacer partícipe al alumnado en el análisis de sus propias representaciones. La actividad 3 de elaboración de insectos, condujo a un proceso de revisión en el que el alumnado se interrogaba continuamente si sus dibujos autogenerados reflejaban con precisión el contenido en las instrucciones materiales. Todo ello nos permite sugerir su inclusión, pudiendo optar el docente por realizar una salida de campo en la que observen y luego dibujen los ejemplares encontrados; o bien, como en el caso de esta secuencia, realizar los dibujos previamente en el aula y contrastarlos posteriormente con ejemplares vivos fáciles de observar en el laboratorio. 
El análisis de actividad 4 muestra dificultades por parte de los/las participantes a la hora de usar criterios de clasificación de plantas. De acuerdo con Strgar (2007), creemos que para superar esta situación es necesario desarrollar tareas específicas con plantas que permitan mejorar la atención y apreciación de estas por parte del alumnado, así como el conocimiento botánico. Una de las competencias botánicas y destrezas científicas básicas que resulta más complicada para el alumnado es clasificarlas (Maskour, Alami, Zaki y Agorram 2019), por lo que es necesario promover tareas de este tipo, siendo necesario su evaluación posterior. El/la docente interesado/a en llevar a cabo puede optar por utilizar otros ejemplares de plantas, próximas al centro e incorporar a la salida de campo la observación de plantas in situ. En caso de existir restricciones de tiempo, es posible una reducción de elementos y condensar las sesiones dedicadas a insectos y a plantas en dos únicas sesiones.

La problemática de la pérdida de abejas y de otros insectos polinizadores constituye un problema socio-científico complejo cuyo análisis requiere el uso de datos relacionados con las distintas causas que lo producen. Involucrar al alumnado en tareas de argumentación, como la de esta unidad, que requieran relacionar datos con conclusiones ayuda a guiar al alumnado en la construcción de argumentos. Sin embargo, los estudiantes pueden establecer relaciones inadecuadas. Sugerimos involucrar al alumnado previamente en el análisis de pruebas a favor o en contra para su posterior aplicación en la elaboración de argumentos.

El/la docente interesado/a en poner en práctica esta secuencia puede optar por simplificar las tareas y utilizar ejemplos más sencillos para su aplicación en distintos niveles, siendo imprescindible para lograr estimular su atención tener en cuenta el contexto en el que se realice y los insectos más comunes y fáciles de observar.

\section{Agradecimientos}

Este trabajo forma parte del Proyecto ESPIGA financiado por FEDER/Ministerio de Ciencia, Innovación y Universidades - Agencia Estatal de Investigación, referencia PGC2018-096581-B-C22 y del grupo de investigación RODA (Razonamiento, Discurso y Argumentación). A los/las participantes del estudio. Gracias a Efrén Álvarez Salvado por su colaboración en el diseño de las Figuras 1 y 2.

\section{Referencias}

Allsopp, M., Lange, W. y Veldtman, R. (2008). Valuing insect pollination services with cost of replacement. PLOS ONE, 3 (9), e3128.

Barrow, L. (2002). What do elementary students know about insects? Journal of Elementary Science Education. 14 (2), 53-60.

Couso, D. (2020). Aprender ciencia involucra aprender ideas potentes de la ciencia: la modelización ayuda a la explicación- predicción de fenómenos. En Couso, D., JiménezLiso, M.R., Refojo, C. y Sacristán, J.A. (Coords) (2020), Enseñando Ciencia con Ciencia. FECYT y Fundacion Lilly. Madrid: Penguin Random House.

Couso, D. (2016). Participatory approaches on curriculum design: a promising paradigm for Science. En Psillos, Dimitris, Kariotoglou, Petros (Eds.) Iterative Design of TeachingLearning Sequences: Introducing the Science of Materials in European School, (pp. 47- 71), Springer.

Díaz-Moreno, N. y Jiménez-Liso M. R. (2011) Las controversias sociocientíficas: temáticas e importancia para la educación científica. Revista Eureka sobre Enseñanza y Divulgación de las Ciencias 9(1), 54-70.

Eilam, B. (2002). Strata of comprehending ecology: looking through the prism of feeding relations. Science Education, 86(5), 645-671. 
Garrido, A. y Couso, D. (2015) Socio-scientific issues (SSI) in initial training of primary school teachers: Pre-service teachers' conceptualization of SSI and appreciation of the value of teaching SSI. Procedia-Social and Behavioral Sciences, 196, 80-88.

González-García, F. (2015) Didáctica de las Ciencias para Educación Primaria: II Ciencias de la vida. Madrid: Pirámide.

Gómez Prado, B.; Puig, B. y Evagorou, M. (2020). Primary pre-service teachers' emotions and interest towards insects. An explorative case study. Journal of Biological Education. doi: https://doi.org/10.1080/00219266.2020.1756896

Gómez Prado, B.; Puig, B.; y Evagorou, M. (2018). ¿Cuáles son las flores favoritas de los polinizadores? Alambique Didáctica de las Ciencias Experimentales, 92, 74-76.

Guisasola-Aranzabal, J., Ametller, J. y Zuza, K. (2020). Investigación basada en el diseño de Secuencias de Enseñanza-Aprendizaje: una línea de investigación emergente en Enseñanza de las Ciencias. Revista Eureka Sobre Enseñanza Y Divulgación De Las Ciencias, 18(1),

1801. https://doi.org/10.25267/Rev_Eureka_ensen_divulg_cienc.2021.v18.11.1801

Guisasola, J. y Oliva, J.M. (2020). Nueva sección de especial de REurEDC sobre investigación basada en el diseño de secuencias de enseñanza. Revista Eureka sobre Enseñanza y Divulgación de las Ciencias, 17(3), 3001.doi: 10.25267/Rev_Eureka_ensen_divulg_cienc.2020.v17.i3.3001

Jewell, N. (2002). Examining Children's Models of Seed. Journal of Biological Education, 36 (3), pp. 116-122.

Jiménez-Aleixandre, M. P. (2020). ¿Cómo sabemos lo que sabemos? Mediante la argumentación y el uso de pruebas, herramientas para aprender y desarrollar el pensamiento crítico. En Couso, D., Jimenez-Liso, M.R., Refojo, C. y Sacristán, J.A. (Coords) (2020). Enseñando Ciencia con Ciencia. FECYT y Fundacion Lilly. Madrid: Penguin Random House.

Jiménez Aleixandre, M. P. y Puig, B. (2013). El papel de la argumentación en clase de ciencias: llevando a cabo prácticas científicas, Alambique Didáctica de las Ciencias Experimentales, 75, 79-90.

Jiménez-Liso, M. R, Hernández-Villalobos L. y Lapetina J. (2010) Dificultades y propuestas para utilizar las noticias científicas de la prensa en el aula de ciencias. Revista Eureka sobre Enseñanza y Divulgación de la Ciencia, 7 (1), 107-126. doi: 10.25267/rev_eureka_ensen_divulg_cienc.2010.v7.11.07

Jiménez-Liso, M. R., Martínez-Chico, M., Avraamidou, L. y López-Gay, R. (2019) Scientific practices in teacher education: The interplay of sense, sensors, and emotions. Research in Science \& Technological Education, 1-24. doi: https://doi.org/10.1080/02635143.2019.1647158

Kellert, S. (1993) Values and perceptions of invertebrates. Conservation Biology, 7(4), 845-855.

Kelly, G. J. (2008). Inquiry, activity and epistemic practice. En R. A. Duschl y R. E. Grandy (Eds.), Teaching scientific inquiry: Recommendations for research and implementation (pp. 99-117). Rotterdam: Sense Publishers.

Klein, A., Vaissière, B., Cane, H., Steffan-Dewenter, I., Cunningham, S., Kremen, C. y Tscharntke, T. (2007). Importance of pollinators in changing landscapes for world crops. Proceedings of the Royal Society B: Biological Sciences, 274(1608), 303-313. 
Licorish, S., George, J., Owen, H. y Daniel, B. (2017) «Go Kahoot!» Enriching classroom engagement, motivation and learning experience with games. Proceedings of the 25th International Conference on Computers in Education, 755-764.

Martí, J. (2012) Aprender ciencias en la educación primaria. Barcelona: Graó.

Maskour L., Alami A., Zaki M. y Agorram B. (2019) Plant classification knowledge and misconceptions among university students in Morocco. Education Sciences, 9 (1), 48.

Merino, J. M., Esteban-Gallego, R. y Gómez-Ochoa, J. (2019). Formando a futuros maestros para abordar los microorganismos mediante actividades prácticas. Papel de las emociones y valoraciones de los estudiantes. Revista Eureka sobre Enseñanza y Divulgación de las Ciencias, 16 (1), $1602 . \quad$ doi: https://doi.org/10.25267/Rev_Eureka_ensen_divulg_cienc.2019.v16.i1.1602

Metz, K. E. (2000). Young children's inquiry in biology: Building the knowledge bases to empower independent inquiry. En J. Minstrell y E. van Zee (Eds.), Inquiring into inquiry learning and teaching in science (pp. 371-404). Washington DC: American Association for the Advancement of Science.

Ollerton, J., Winfree, R. y Tarrant, S. (2011). How many flowering plants are pollinated by animals? Oikos, 120 (3), 321-326.

Osborne, J. (2017). Teaching Scientific Practices: Meeting the Challenge of Change. Journal of Science Teacher Education, 25 (2), 177-196. doi: https://doi.org/10.1007/s10972-0149384-1

Osborne, J., Simon, S., Christodoulou, A., Howell-Richardson, C. y Richardson, K. (2013) Learning to argue: A study of four schools and their attempt to develop the use of argumentation as a common instructional practice and its impact on students. Journal of Research in Science Teaching, 50(3), 315-347.

Puig, B. (2015). ¿Sería posible un mundo sin abejas? Alambique Didáctica de las Ciencias Experimentales, 75-76.

Puig, B. y Evagorou, M. (2020). Design of a Socioscientific Issue Unit with the Use of Modeling: The Case of Bees. International Journal of Designs for Learning, 11 (1). doi: https://doi.org/10.14434/ijdl.v11i1.24142

Roth, W. M. (2014). Curriculum*-in-the-making: A post-constructivist perspective. Nueva York: Peter Lang.

Sánchez-Bayo, F. y Wyckhuys, K. (2019) Worldwide decline of the entomofauna: a review of its drivers. Biological Conservation, 232, 8-27.

Sandoval, W., y Bell, P. (2010). Design-Based Research Methods for Studying Learning in Context: Introduction. Educational Psychologist. 39. 199-201. doi: 10.1207/s15326985ep3904_1.

Schussler, E., y Winslow, J. (2007). Drawing on students' knowledge about plant life cycles. Science and Children, 44, 40-44.

Strgar, J. (2007. Increasing the interest of students in plants. Journal of Biological Education, 42(1), 19-23.

Van Meter, Peggy y Garner, Joanna. (2005). The Promise and Practice of Learner-Generated Drawing: Literature Review and Synthesis. Educational Psychology Review. 17. 285-325. doi: 10.1007/s10648-005-8136-3. 
Wagler, R. (2010). The association between preservice elementary teacher animal attitude and likelihood of animal incorporation in future science curriculum. International Journal of Environmental and Science Education, 5(3), 353-375.

Wagler, R. y Wagler, A. (2011) Arthropods: Attitude and Incorporation in Preservice Elementary Teachers. International Journal of Environmental and Science Education, 6(3), 229-250.

Wagler, R. y Wagler, A. (2012) External Insect Morphology: A Negative Factor in Attitudes toward Insects and Likelihood of Incorporation in Future Science Education Settings. International Journal of Environmental and Science Education, 7(2), 313-325.

Wandersee, J. y Schussler, E. (2001) Toward a Theory of Plant Blindness. Plant Science Bulletin, 47(1), 2-9.

Watanabe, M. (2008) Colony Collapse Disorder: Many Suspects, No Smoking Gun. BioScience, 5(5), 384-388. 